\title{
Representações sociais acerca do futuro do usuário de crack: o que esperar?
}

\author{
Social representations about future of crack users: what to expect?
}

\author{
Naiara França da Silva ${ }^{1}$ \\ André Faro ${ }^{2}$
}

\begin{abstract}
RESUMO: Pela velocidade com que o crack tem ganhado lugar na sociedade, e por hoje ser considerado um grande problema social, este trabalho buscou analisar as representações sociais da expectativa de futuro do usuário de crack e ao seu uso, na perspectiva de usuários, familiares e profissionais de saúde. O estudo foi desenvolvido de acordo com o referencial da Teoria do Núcleo Central. A pesquisa foi realizada em quatro CAPS (Centro de Atenção Psicossocial), onde foram entrevistados trinta usuários de crack, vinte familiares e trinta profissionais de saúde. $\mathrm{Na}$ coleta de dados foram utilizadas associações livres com base na técnica de evocações, organizadas e processadas através do software EVOC. Nos resultados constatou-se a ausência de perspectivas de mudança entre os grupos, no que se refere ao futuro do usuário de crack, sendo notória a descrença em relação a sua recuperação, principalmente para usuários e familiares. Estes resultados sinalizam importantes preocupações, tais como os desafios enfrentados pelos profissionais de saúde em sua atuação frente à dependência do crack e às dificuldades de tratamento e medidas de prevenção. Portanto, espera-se que este trabalho proporcione subsídios para a elaboração de estudos futuros na área da psicologia social e da saúde mental, embasando ações que ampliem a atenção a esses usuários, bem como a sua aderência ao tratamento.
\end{abstract}

Palavras-chave: representações sociais; evocações livres; crack (droga); usuários.

ABSTRACT: Due to the speed at which the crack has earned place in society and because it has been considered, nowadays, a major social problem, this work aimed to analyze the social representations of the expected to the future of crack users and its use in the perspective of users, their families and health professionals. The study was conducted according to the referential of the Theory of Central Core. The survey was conducted in four Psychosocial Care Centers, where thirty crack users, twenty relatives and thirty health professionals were interviewed. In data collection, free associations were used based on the technique of evocations, which were organized and processed through software EVOC. The results showed the absence of changes prospect with regard to the future of the crack users among the groups and a noticeable disbelief toward his recovery, especially for users and family members. These results indicate important concerns, such as the challenges faced by health professionals in its operations against the crack addiction and the difficulties of treatment and prevention measures. Therefore, it is expected that this study will provide subsidies for the development of future studies in the area of social psychology and mental health, supporting actions that bring attention to these users, as well as their adherence to treatment.

Keywords: social representations; free evocations; crack cocaine; users.

O crescente número de usuários de crack no Brasil tem sido motivo de preocupação para autoridades governamentais, profissionais de diversas áreas e familiares, devido aos numerosos danos causados à sociedade e aos próprios usuários. Por ser uma droga de baixo custo, foi difundida rapidamente, atingindo, hoje, todas as classes sociais e faixas etárias.

\footnotetext{
1 Mestre em Psicologia Social pela Universidade Federal de Sergipe - São Cristóvão, SE, Brasil. E-mail: naiarafs_psico@yahoo.com.br.

2 Doutor em Psicologia Social pela Universidade Federal da Bahia - Salvador, BA, Brasil.
} 
Apesar de ter chegado ao país há mais de duas décadas, o combate a essa substância parece ser um desafio que só foi percebido nos últimos anos.

A conclusão do Relatório Mundial sobre Drogas, em 2013, apontou que a produção e o uso de substâncias psicoativas permanecem estáveis, se comparado ao último relatório, em 2009. Contudo, no Brasil se verificou um aumento no índice de consumo de drogas. Visando a cada ano buscar melhorias para essas regiões e criar novas medidas de prevenção, 0 Escritório das Nações Unidas sobre Drogas (UNODC) garante que tem trabalhado para que essa problemática não se agrave, visto que as drogas ilícitas põem em risco o bem-estar de todos, não somente do usuário. Segundo o Relatório Mundial, essas drogas podem ter um impacto mortal sobre os usuários, reverberando sobre seu meio, pois ameaçam a estabilidade e a segurança de todo o mundo, com prejuízos econômicos e sociais (UNODC, 2013).

No Brasil, o II Levantamento Nacional de Álcool e Outras Drogas (LENAD) mostrou que o país é o maior mercado de crack do mundo, além de afirmar que o mesmo representa $20 \%$ do consumo mundial de cocaína/crack. Esta pesquisa apontou que há, aproximadamente, 2,8 milhões de usuários de crack no Brasil - entre jovens e adultos (Laranjeira et al., 2012). Tais dados são preocupantes, considerando os prejuízos que essa droga traz para a vida dos usuários, seus familiares e sociedade em geral, sendo considerado um notável problema social e de saúde pública.

Os usuários regulares de crack e/ou de formas similares de cocaína fumada (pastabase, merla e oxi) somam 370 mil pessoas nas 26 capitais brasileiras e no Distrito Federal. Essa população representa $35 \%$ do total de consumidores de drogas ilícitas, estimado em 1 milhão de brasileiros. O levantamento mostra, ainda, que, dentre os 370 mil usuários de crack e/ou similares, $14 \%$ são menores de idade. Isso indica que, aproximadamente, 50 mil crianças e adolescentes usam regularmente essa substância nas capitais do país (Bastos \& Bertoni, 2014).

Considerando a complexidade dos fatores existentes no uso do crack, faz-se importante sua compreensão a partir das diversas relações que os indivíduos estabelecem com a substância e os significados atribuídos a esta, pois, como mencionado em Haas, Angonese e Oliveira (2011), os usuários possuem baixa autoestima relacionada a uma autoimagem que retrata a face da dependência, o que faz com que acabem se conformando a viver dessa forma, ainda que não estejam felizes. Para eles, a urgência em conseguir a droga parece mais importante.

A partir desses pressupostos, buscou-se subsídios numa teoria que possibilitasse uma maior compreensão acerca da drogadição na visão dos próprios envolvidos. Com efeito, o estudo das representações sociais mostra-se adequado para a investigação da temática do crack, especialmente no que se refere à análise estrutural das representações sociais que, nesta pesquisa, justifica-se pela possibilidade de identificar os elementos mais significativos nos discursos dos atores envolvidos mais diretamente no cotidiano do uso de crack, a saber: o próprio usuário, seus familiares mais próximos e os profissionais que trabalham cotidianamente com esse público. Assim, frente à gravidade dos problemas acarretados pelo uso do crack, surge a necessidade de atenção para cada um dos atores envolvidos (Duailibi, Ribeiro \& Laranjeira, 2008).

Como bem salientado por Vargens, Cruz e Santos (2011), os dependentes dessa substância formam um grupo distinto entre os usuários de drogas, lícitas ou ilícitas, com peculiaridades e necessidades de tratamento ainda estão parcialmente desconhecidas. 
Inserido nesse processo, os profissionais de saúde relacionam-se diretamente com o usuário de crack, e a sua forma de agir perante o mesmo, pode ter implicações importantes no seu tratamento. Ao tratar desse assunto, surge a questão que norteia o presente estudo: Quais as relações das representações sociais com as práticas e condutas, no que diz respeito à perspectiva de futuro do usuário de crack?

Entende-se tal questionamento como relevante, pois julga-se fundamental conhecer de que forma o crack e os próprios usuários de crack estão sendo percebidos na teia de relações sociais que envolvem a temática. A partir desse pressuposto, acredita-se que, através dessas representações, a compreensão das condutas de cada grupo em relação ao crack seja alcançada, além de ter grande relevância para o campo das políticas públicas.

Em acordo com o debate acima incitado, o objetivo desta pesquisa foi compreender as representações sociais da expectativa de futuro dos usuários de crack na perspectiva de usuários, familiares e profissionais de saúde inseridos no CAPS (Centro de Atenção Psicossocial), além de descrever o conteúdo e a estrutura dessas representações sociais na concepção dos atores sociais estudados.

\section{Método}

\section{Participantes}

Mediante critério de saturação, os indivíduos foram selecionados por terem experienciado o fenômeno central, sendo utilizada uma amostra intencional. Os critérios de inclusão foram: a) Os usuários de crack deveriam estar em acompanhamento no CAPS; b) Os profissionais deveriam manter um contato direto com estes usuários; e c) O familiar deveria ter vivenciado e acompanhado as consequências do crack na vida do usuário.

Semelhante a resultados descritos em estudos anteriores (Nappo, Galduróz \& Noto, 1996; Oliveira \& Nappo, 2008; Sanchez \& Nappo, 2007), os usuários de crack que fizeram parte da amostra deste estudo são, em sua maioria, do sexo masculino (83,3\%), sendo a média de idade 27,1 ( $D P=7,23)$, solteiros $(80,0 \%)$, de baixo nível socioeconômico $(66,7 \%$ não possuem renda), baixo grau de escolaridade (com 76,7\% dos usuários sem o ensino fundamental completo) e sem vínculos empregatícios formais (73,3\%). Participaram da pesquisa vinte familiares de usuário de crack, com idade entre 22 a 58 anos, com média de 39,5 (DP = 11,6), havendo prevalência do gênero feminino, tendo participado da amostra 12 mulheres $(60,0 \%)$ e 8 homens $(40,0 \%)$. Tal qual estudos que avaliaram o perfil de trabalhadores de saúde mental (Ballarin, Carvalho, Ferigato \& Miranda, 2011; Martins, 2009), houve, nesta amostra, o predomínio de profissionais do sexo feminino, sendo 23 mulheres $(76,7 \%)$ e 7 homens $(23,3 \%)$.

Ao final, a amostra deste estudo foi composta por 30 usuários de crack, 20 familiares e 30 profissionais inseridos nos CAPS, totalizando uma amostra de 80 participantes. A pesquisa foi realizada em quatro CAPS, sendo três localizados no interior do estado de Sergipe e um na capital, Aracaju. Apenas este último é classificado como CAPS AD, destinando-se a usuários de álcool e outras drogas.

\section{Instrumentos}

Os dados foram coletados por meio de associações livres, baseando-se na técnica de evocações, que busca acessar a organização e a estrutura interna da representação social 
analisada. Com base nessa técnica se perguntou aos participantes: "O que vem à sua mente quando você pensa em futuro do usuário de crack?". As palavras evocadas foram registradas pela pesquisadora no instrumento de coleta de dados, sendo consideradas para a análise as primeiras 3 evocações. Além das evocações, utilizou-se a entrevista como instrumento de coleta de dados, o que permitiu a caracterização dialógica das evocações emitidas. A entrevistadora registrou as falas obtidas através da entrevista para serem utilizadas na contextualização e exemplificação dos resultados da análise de evocações.

\section{Procedimentos}

Estabeleceu-se um contato prévio com as instituições escolhidas e foram entregues as Solicitações de Autorização para a Pesquisa, nas quais estavam descritos os critérios éticos da pesquisa e seus objetivos, assim como o Termo de Consentimento Livre e Esclarecido, assinado pelos participantes e/ou responsáveis legais. Conforme resolução CNS № 466, de 12 de dezembro de 2012, do Conselho Nacional de Saúde acerca de pesquisas realizadas com seres humanos, o projeto de pesquisa foi submetido e aprovado pelo Comitê de Ética em Pesquisa com Seres Humanos.

\section{Análise de dados}

Com base na abordagem estrutural das representações sociais (Abric, 2000; Sá, 1996), a pesquisa do núcleo central, viabilizada pelas associações coletadas, deu-se através (1) da saliência dos elementos da representação e (2) da conexidade entre tais elementos. Para análise de evocações, os dados foram organizados e processados através do software Ensemble de Programmes Permettant l'Analyse dês Évocation (EVOC). Ele realiza a análise estatística das evocações dos participantes em um esquema que considera tanto a frequência de aparição das respostas, quanto a ordem em que elas são evocadas. É a partir da interação entre os critérios de frequência e ordem de evocação, que é definida a importância das respostas e seu tipo de relação com o termo indutor (Vergès, 2002), os quais são alocados em quadrantes com atribuições peculiares (Quadro de Quatro Casas) dentro da teoria estrutural das representações sociais.

O software EVOC, por um de seus programas -Rangfrq, permite a identificação da frequência de cada elemento do corpus levando em conta ordem dos vocábulos registrados pelos participantes; distribuindo-os em um quadro de quatro casas, viabilizando análises prototípicas. $\mathrm{O} 1 \mathrm{Q}$ quadrante se refere aos elementos mais relevantes e, por isso, possíveis de constituírem o núcleo central de uma representação. Estes elementos são os mais prontamente evocados e citados com frequência elevada pelos sujeitos. No $2 \circ$ quadrante estão os elementos que obtiveram uma frequência alta, mas que foram citados em últimas posições; no 3 o quadrante, também denominado Zona Contraste (ZC), encontram-se os elementos que foram citados numa frequência baixa, porém foram evocados primeiramente. No 4ㅇ quadrante estão os elementos que correspondem à periferia distante ou segunda periferia. Nele estão os elementos menos citados e menos evocados em primeira mão pelos sujeitos (Oliveira, 2013; Sá, 1996).

Analisou-se também outro de seus programas, o AIDECAT, que informa a frequência da relação entre os elementos identificados pelo Rangfrq, no qual se calcula a coocorrência dos termos evidenciados no quadro de quatro casas, visto que se parte do pressuposto de que as palavras evocadas pelos sujeitos guardam relação entre si, encontrando-se, pois, em 
situação de conexidade espontânea, revelando as palavras que mantêm aproximação entre si nos discursos.

\section{Resultados e discussão}

Buscando conhecer as representações sociais da expectativa de futuro de um indivíduo que consome o crack, foi realizada uma análise comparativa entre as evocações apresentadas pelos grupos em questão (usuários, familiares e profissionais), a partir do termo indutor futuro do usuário de crack, buscando identificar semelhanças e discrepâncias em seus discursos.

Na Tabela 1 pode-se observar a comparação entre as evocações apresentadas pelos grupos, dispostas no quadro de quatro casas. Segundo Sá (1996), o que vai caracterizar uma representação vai ser o núcleo central, uma vez que este elemento lhe atribui estabilidade e identidade. Nesse sentido, será mais estável e resistente a mudanças e influências do meio. Caso ocorra alguma mudança no elemento central, toda a representação sofrerá modificação. Nos resultados encontrados, podem-se notar algumas diferenças interessantes em relação às evocações no núcleo central dos participantes. No grupo dos usuários, os termos prisão e morte podem revelar um caráter fatalista do futuro do usuário de crack - ou ele será preso ou morto. Essa afirmativa sugere que os usuários entrevistados possivelmente não possuem perspectivas de mudança, sendo notória a descrença dos mesmos em relação a sua recuperação. Tal perspectiva ainda se mostra mais relevante, pois são indivíduos acompanhados no CAPS, visto que essa foi uma característica de inclusão na amostragem.

Como elemento central na representação desse grupo, o termo morte foi citado como o "fim do poço", no sentido de ser esta uma consequência direta do uso do crack, como bem descrita na seguinte frase: "O usuário de crack é uma pessoa que não tem mais jeito na vida, não tem mais retorno, ou ele vai pra cadeia ou vai morrer, não tem outro caminho" (Usuário 8, 27 anos). No entanto, a literatura aponta que a relação existente entre o uso de crack e a mortalidade não acontece de forma direta, uma vez que o índice crescente de óbitos entre usuários dessa droga são mais frequentemente associados ao entorno violento, do que à própria substância (Kessler \& Pechansky, 2008).

Tabela 1 - Esquema Comparativo do Quadro de Quatro Casas a partir das Enunciações sobre o Termo Indutor "Futuro do Usuário de Crack"

\begin{tabular}{|c|c|c|c|c|c|c|c|c|}
\hline \multicolumn{9}{|c|}{$\begin{array}{c}\text { Núcleo Central } \\
\text { Frequência } \geq 11 \text { e Classificação Média }<1,5\end{array}$} \\
\hline \multicolumn{2}{|c|}{ Usuários } & & \multicolumn{3}{|c|}{ Familiares } & \multicolumn{3}{|c|}{ Profissionais } \\
\hline Enunciações* & Freq. ${ }^{1}$ & $\mathrm{OME}^{2}$ & Enunciações & Freq. & OME & Enunciações & Freq. & OME \\
\hline Prisão & 90 & 1,167 & Tratamento & 25 & 1,200 & Abandono & 15 & 1,000 \\
\hline \multirow[t]{2}{*}{ Morte } & 45 & 1,444 & Incerteza & 15 & 1,333 & Apoio & 15 & 1,333 \\
\hline & & & & & & Esperança & 15 & 1,333 \\
\hline \multicolumn{9}{|c|}{ 1a Periferia } \\
\hline \multicolumn{3}{|c|}{ Usuários } & \multicolumn{3}{|c|}{ Familiares } & \multicolumn{3}{|c|}{ Profissionais } \\
\hline Enunciações & Freq. & OME & Enunciações & Freq. & OME & Enunciações & Freq. & OME \\
\hline Roubo & 20 & 1,500 & & & & Tratamento & 50 & 1,600 \\
\hline Mendicância & 15 & 1,667 & - & - & - & Morte & 50 & 1,700 \\
\hline Abandono & 20 & 2,000 & & & & & & \\
\hline
\end{tabular}




\begin{tabular}{|c|c|c|c|c|c|c|c|c|}
\hline \multicolumn{9}{|c|}{ Zona de Contraste } \\
\hline \multicolumn{2}{|c|}{ Usuários } & & \multicolumn{3}{|c|}{ Familiares } & \multicolumn{3}{|c|}{ Profissionais } \\
\hline Enunciações & Freq. & OME & Enunciações & Freq. & OME & Enunciações & Freq. & OME \\
\hline \multirow{5}{*}{ 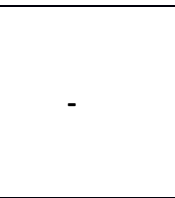 } & \multirow{5}{*}{-} & \multirow{5}{*}{-} & Prisão & 20 & 1,500 & \multirow{2}{*}{$\begin{array}{l}\text { Força_de_- } \\
\text { vontade }\end{array}$} & \multirow[t]{2}{*}{10} & \multirow[t]{2}{*}{1,000} \\
\hline & & & Cura & 15 & 1,667 & & & \\
\hline & & & Mendicância & 15 & 1,667 & Internação & 10 & 1,000 \\
\hline & & & \multirow[t]{2}{*}{ Morte } & 35 & 1,857 & Justiça & 10 & 1,000 \\
\hline & & & & & & Prisão & 10 & 1,000 \\
\hline \multirow{2}{*}{\multicolumn{9}{|c|}{ 2a Periferia }} \\
\hline & & & & & & & & \\
\hline \multicolumn{2}{|c|}{$\underline{\text { Usuários }}$} & & \multicolumn{3}{|c|}{ Familiares } & \multicolumn{2}{|c|}{ Profissionais } & \\
\hline Enunciações & Freq. & OME & Enunciações & Freq. & OME & Enunciações & Freq. & OME \\
\hline Doença & 10 & 1,500 & Tristeza & 10 & 1,500 & Ajuda & 10 & 1,500 \\
\hline Desprezo & 10 & 2,000 & Mudança & 10 & 2,000 & Derrota & 10 & 2,000 \\
\hline Loucura & 10 & 2,000 & & & & Destruição & 10 & 2,000 \\
\hline \multirow[t]{3}{*}{ Tristeza } & 10 & 2,000 & & & & Recaída & 10 & 2,000 \\
\hline & & & & & & Solidão & 10 & 2,000 \\
\hline & & & & & & Superação & 10 & 2,000 \\
\hline
\end{tabular}

Notas. *Aplicada uma constante para o cálculo das enunciações (x 5). ${ }^{1}$ Frequência Absoluta; ${ }^{2}$ Ordem Média de Evocação.

A palavra prisão foi citada mais vezes e evocada mais prontamente, o que indica que possui significação mais pregnante na representação. Esse pensamento parece refletir a realidade vivenciada pelos usuários de crack. Entre os usuários que participaram da pesquisa, 63,3\% afirmaram já ter enfrentado problemas judiciais e policiais. Essa situação é complexa, porque se compreende que o usuário de droga demanda tratamento para a sua dependência química, no entanto, motivado pela fissura e pela necessidade de consumir essas substâncias, o indivíduo é capaz de cometer desde furtos a homicídios. Segundo Kessler e Pechansky (2008), as regiões com maior número de consumo de crack têm sido os locais com maiores índices de violência e de criminalidade. Deste modo, considerando as implicações advindas dessa conjuntura, é necessário pensar formas de combate permanentes frente ao uso dessa droga.

De acordo com as OMEs apresentadas, as evocações tratamento e incerteza foram elementos que denotaram maior centralidade no grupo dos familiares. Estas expressões vão dar sentido às demais, gerando o significado da representação e determinando a sua organização (Wilbert, 2009), ou seja, os sentidos atribuídos às outras evocações se relacionam aos elementos presentes no núcleo central. Dentre os elementos nucleares, a palavra tratamento apresentou maior importância entre os familiares, visto que teve uma maior frequência e menor OME. Para Abric (2000), é no núcleo central onde se concentram as palavras mais frequentes e mais importantes da representação, lembrando que ele comporta as funções de gerar o significado da representação, determinar sua organização e manter sua estabilidade. Isso sugere que este grupo acredita, ou espera, que o membro familiar que faz uso do crack possa aderir ao tratamento para cuidar da dependência química. O vocábulo incerteza mantém ligação com o termo tratamento nos discursos dos familiares entrevistados, indicando que, apesar de estes acreditarem no tratamento como uma forma de livrar o usuário do crack, eles sentem-se inseguros em relação à sua aderência e desfecho. Enfim, este grupo demonstrou, através das evocações tratamento e incerteza, desejar que o membro familiar o qual faz uso dessa droga, busque um tratamento para tentar abandoná-la, no entanto, parece não acreditar que isso possa ser concretizado, pois as recaídas são frequentes. Isso pode ser exemplificado com a seguinte fala: 
É difícil ele [o usuário de crack] querer a nossa ajuda, só quando tá muito mal, por isso que tem que conversar antes, porque depois que começa a usar fica difícil querer tratamento (Mãe de usuário de crack, 46 anos).

Essa suposta descrença remete ao pensamento de que as propostas de acompanhamento, disponibilizadas ao usuário, ainda não gozam da confiabilidade, pelo menos desejada por quem vivencia a realidade de ter um familiar dependente da droga. Em outras palavras, os familiares acreditam que o poder destrutivo que o crack possui seja mais forte do que as estratégias que vêm sendo utilizadas atualmente no sistema de saúde, no que se refere ao tratamento voltado para dependentes químicos, especialmente relacionado ao uso do crack.

Já os profissionais de saúde, expressaram percepções mais positivas, embora com ressalvas. Como podem ser verificadas na Tabela 1, as evocações que compõem o núcleo central possuem significações semelhantes na representação, salvo o termo abandono, que apresentou uma menor ordem média. Esse vocábulo refere-se, nos discursos dos entrevistados, à solidão e ao abandono do tratamento pelo usuário. Pode-se interpretar tal associação de maneira a supor que os profissionais acreditam que, caso o usuário desista do tratamento e continue o consumo do crack, as consequências advindas desse comportamento podem levá-lo ao abandono social, incluindo da família. Essa preocupação pode ser observada através da seguinte fala:

Eu acho que com ajuda ele pode estar se recuperando, ele precisa de ajuda. Eu vejo como uma pessoa com muita dificuldade para sair dessa dependência, é uma pessoa prejudicada. Assim, sem forças, sem perspectivas na vida, sem projeto nenhum de vida. É usar o crack e perder toda perspectiva de futuro. A não ser que consiga se tratar e sair desse vício (Enfermeiro, 32 anos).

O núcleo central do discurso dos profissionais foi composto, ainda, pelos vocábulos apoio e esperança, sugerindo uma visão diferenciada em relação aos demais grupos. Sobre o apoio, os profissionais relataram que os usuários precisam ser amparados e o relacionou ao tratamento e à ajuda, de forma a entender que, para aderir e manter-se no tratamento, se faz necessário apoiá-los. Quanto à esperança, relacionada à internação, ao tratamento e à morte, demonstra que, para esse grupo, a única maneira de o usuário de crack evitar maiores prejuízos à sua vida é buscar uma internação, a fim de que possa ocorrer a sua recuperação. Um dos profissionais entrevistados relatou bem a dificuldade encontrada na adesão do indivíduo ao tratamento:

Pelo que conheço desse grupo, posso dizer que o usuário de crack se torna escravo da substância. É ser dependente de algo que só destrói sua vida, suas relações, seu futuro. Por mais vontade que a pessoa demonstre ter em relação a um tratamento, quando fica em abstinência e a fissura ataca, não enxerga mais nada na frente, passa por cima de tudo que tava reconstruindo e volta para as drogas (Psiquiatra, 42 anos).

Entre os elementos localizados na primeira periferia, que comportam os elementos periféricos mais salientes, em razão de serem também os mais frequentes (Abric, 2000), pode-se perceber que os usuários e os profissionais apresentaram evocações pertinentes àquelas que compõem o núcleo central. As palavras roubo, mendicância e abandono dão contexto aos elementos nucleares encontrados no grupo dos usuários, sugerindo que as condutas que estes possuem quando buscam meios de conseguir a droga, como o ato de roubar, possa levá-los à prisão; assim, em decorrência do abandono e das condições de vida que a sua realidade os impõem, configuram-se como riscos à própria vida. Seguindo essa lógica, parece que os usuários de crack não veem outro caminho para seu futuro, que não seja a prisão ou a morte, como visto no núcleo central. 
No grupo dos profissionais de saúde, as evocações tratamento e morte remetem às ideias centrais que possuem acerca desse futuro. Logo, o tratamento está relacionado à esperança de mudar o seu destino, e a morte seria em decorrência dos riscos associados ao uso de crack:

Eu acho que com ajuda, ele pode estar se recuperando, ele precisa de ajuda, de um tratamento. É usar o crack e perder toda perspectiva de futuro. A não ser que consiga se tratar e sair desse vício (Enfermeiro, 32 anos).

Importante frisar que, no grupo dos familiares, não apareceu nenhuma evocação na primeira periferia, aludindo que o pensamento compartilhado entre este grupo sobre o futuro do usuário de crack parece aproximar-se do consensual entre os participantes. Esse dado indica certa homogeneidade entre o grupo estudado. Entende-se que os elementos localizados na primeira periferia costumam contextualizar as representações situadas no núcleo central (Wilbert, 2009), o que sugere uma noção de estabilidade para os termos tratamento e incerteza do núcleo central.

De maneira semelhante, percebe-se a ausência de elementos na zona de contraste no grupo dos usuários, que, segundo Oliveira, Marques e Tosoli (2005, p. 4), "comporta elementos que caracterizam variações da representação em função de subgrupos, sem, no entanto, modificar os elementos centrais e a própria representação". A ausência de elementos na zona de contraste, na qual se encontram os temas enunciados por poucas pessoas, apresentando, portanto, baixa frequência, pode indicar a ausência de outras possibilidades representativas para o grupo, não trazendo outros modos de perceberem a questão. Conforme Abric (2000), a zona de contraste pode revelar indícios da existência de um subgrupo minoritário portador de uma representação diferenciada.

No caso dos familiares e profissionais, nota-se que há um elemento em comum entre os grupos (prisão) na zona de contraste, denotando a visão negativa que possuem acerca do futuro do usuário de crack. Os participantes desses grupos parecem sentir-se inseguros quanto à possibilidade de recuperação daqueles indivíduos, pois reconhecem a probabilidade de reincidência entre os dependentes químicos.

Ainda sobre a zona de contraste, verificou-se que os familiares acreditam numa cura (espiritual/religiosa) para a dependência do membro familiar que faz uso da droga. A partir disso, pode-se entender que as abordagens de tratamento ofertadas pelos serviços públicos parecem não ser suficientes na resolução dessa questão, cooperando para a necessidade da busca de novos alicerces nessa batalha contra o crack. No grupo dos profissionais, chamou a atenção a evocação força de vontade, pois responsabiliza aos próprios usuários, o sucesso ou o fracasso do seu tratamento. Tal achado se mostra bastante problemático, já que se volta a uma crença bem arraigada no senso comum, o que provavelmente não era esperado. Menciona-se tal problema uma vez que a força de vontade não se configura exatamente como um aporte técnico para lidar com a drogadição, em especial no caso do crack, o que parece menosprezar, de certa maneira, o elevado poder de dependência e magnitude da abstinência diante da droga, além de sugerir alguma hesitação frente à efetividade das propostas de acompanhamento, ofertadas institucionalmente, por eles mesmos.

$\mathrm{Na}$ segunda periferia encontram-se aquelas expressões individuais, relacionadas ao contexto experiencial de cada grupo em seu cotidiano (Rocha, 2010), que, de acordo com Abric (2000), congrega os elementos um pouco menos presentes ou importantes no campo das representações. Assim, através da evocação tristeza, comum aos grupos dos usuários e dos familiares, percebe-se que a desesperança na recuperação dos usuários de crack é 
compartilhada entre os envolvidos. Embora a palavra mudança também tenha sido evocada por parte dos familiares entrevistados, a incerteza a respeito do futuro do usuário predominou nos discursos analisados, considerando o elevado nível de dependência e poder destrutivo da droga. Em relação aos profissionais de saúde, observa-se que a maioria das evocações possuem sentidos negativos, o que sugere uma visão pessimista em relação ao futuro do usuário de crack. Essa concepção implica em questionamentos voltados para a qualidade dos serviços ofertados atualmente, pois, havendo insegurança entre os profissionais, é possível que a sua atuação sofra algum tipo de influência.

A partir do que foi exposto, pode-se entender que, para os três grupos, o futuro do usuário de crack sugere insucesso. Isso porque a sensação intensa e fugaz provocada pelo crack dificulta o seu abandono por parte dos usuários, comprometendo a sua aderência ao tratamento. Sabe-se que não existe um tratamento direcionado ao usuário de crack, em distinção de outras drogas, visto que ainda não foi encontrada a melhor estratégia ou política para combater e/ou prevenir o seu uso.

A Figura 1 aponta as palavras que mantêm relação entre si nos discursos dos usuários de crack, sendo evidenciadas as conexões entre os termos analisados. O termo prisão foi associado às palavras morte, mendicância, loucura e abandono. Essa inter-relação aponta para consequências do uso do crack e reforça a ideia de incerteza no que se refere às perspectivas para o futuro do usuário de crack. Os próprios usuários parecem não acreditar que possam ter um destino diferente, visto que os efeitos do uso dessa substância são complexos e interferem diretamente na forma de viver. $O$ que se pensa em relação a isso, é que o usuário que faz uso do crack se vê tão dependente, que seus vínculos sociais, familiares e afetivos são rompidos e, abandonados à própria sorte, vivem como mendigos. Quando não na prisão, a morte surge nos discursos como desfecho mais comum.

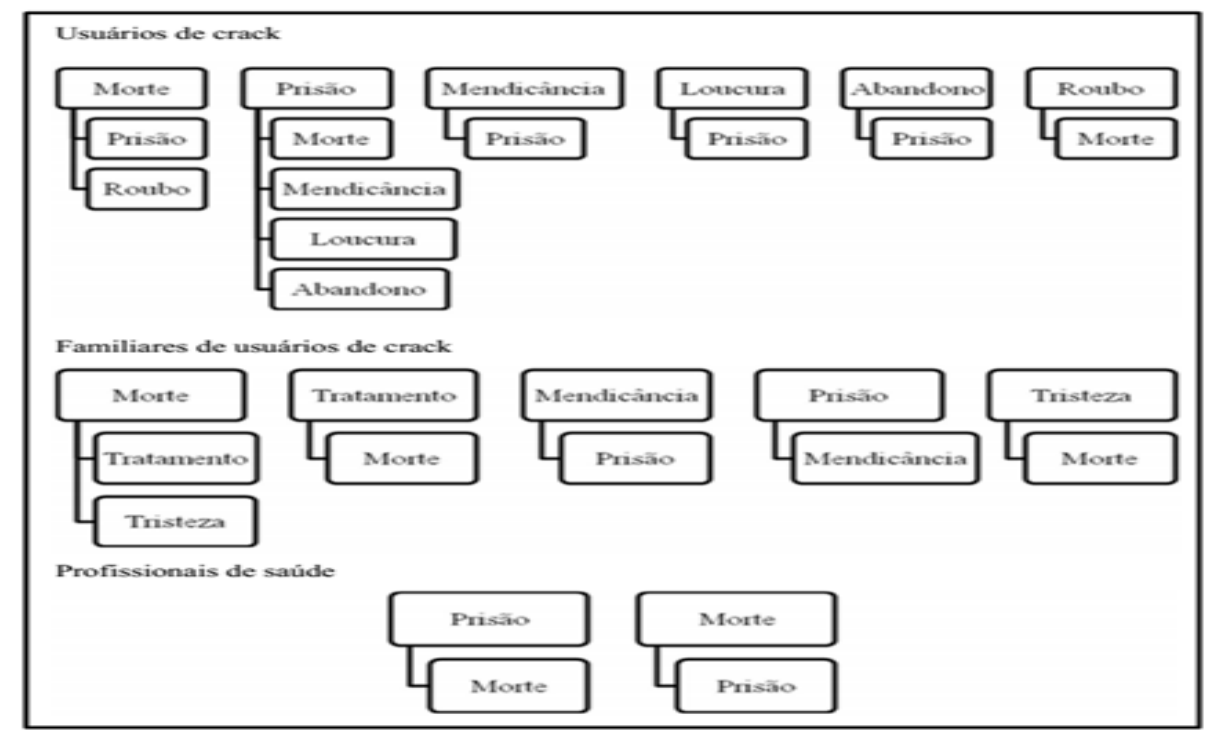

Figura 1 - Matrizes de Coocorrência (EVOC) para o Termo Futuro do Usuário de Crack segundo usuários de Crack, familiares de usuários e profissionais de saúde.

Os termos morte e roubo também mantêm relação entre si, considerando que, para conseguir a droga no momento de abstinência, os usuários afirmaram ser capazes de "roubar, agredir e até matar" (Entrevistado 10, 23 anos). Nesse sentido, essas palavras estão 
associadas a comportamentos comumente atribuídos aos usuários de crack, reforçando a associação entre uso de crack e a violência.

Acredita-se que a perspectiva de desesperança quanto ao futuro dos usuários de crack, segundo eles mesmos, reflete o atual cenário de epidemia da droga. Conforme a literatura (Beck Júnior, 2010; Pratta \& Santos, 2006; Scheffer, Pasa, \& Almeida, 2010), essa droga tem devastado famílias e destruído a vida de milhões de pessoas. Supõe-se que a escassez de serviços especializados em dependência química e as estratégias inadequadas utilizadas no tratamento dessa droga, desmotivam e instalam a desesperança entre os envolvidos.

A respeito do estudo das representações sociais, Jodelet (2001, p. 17) assinala: “As representações sociais devem ser estudadas articulando-se elementos afetivos, mentais e sociais e integrando as relações sociais que afetam as representações e a realidade material, social e ideativa sobre a qual elas têm de intervir". Assim, a importância em conhecer as representações sociais de usuários de crack sobre seu futuro reside na possibilidade de reconhecer os seus anseios e dificuldades, podendo, dessa forma, serem criadas ações e diretrizes voltadas para a realidade daqueles que vivenciam essa questão.

Nos discursos dos familiares de usuários de crack que participaram da pesquisa, verificou-se que as palavras morte, tratamento, mendicância, prisão e tristeza foram associadas entre si. A inter-relação entre essas evocações está ilustrada na Figura 1. Pode-se notar que a evocação morte se relaciona às palavras tratamento e tristeza, revelando percepções importantes dos familiares, concernentes ao futuro do usuário.

Utilizando uma linguagem simples e considerando a associação existente entre estes termos - morte e tratamento -, pode-se supor que, para este grupo, podem haver duas condições para este usuário: ou se trata, ou morre. Segundo familiares entrevistados, parece não existir meio termo, é preciso que o indivíduo faça adesão ao tratamento proposto para dependentes químicos, caso contrário, não vê outro destino para eles, senão a morte. Vale ressaltar que essa possibilidade de morte é relatada, considerando a relação que há entre o uso de crack e a criminalidade, e nem tanto aos efeitos físicos da droga. Sobre a associação morte/tristeza, é enfatizado o quanto o uso de crack atinge toda a família, causando rupturas e sofrimento. Esta concepção se relaciona ao sofrimento causado, ao usuário e a sua família, pelos malefícios gerados por essa substância psicoativa:

Só traz a destruição e a morte. Esse crack destrói uma família completa (Mãe de usuário de crack, 48 anos).

Para os familiares, os termos mendicância e prisão estão associados no sentido de que, vivendo na rua, o usuário está mais suscetível a se envolver em confusões e, consequentemente, ser apreendido pela polícia. Portanto, precisam ser amparados, para que situações como estas sejam evitadas. Corroborando com Matos, Pinto e Jorge (2008), a família deve ser incluída no cuidado e atenção, no que diz respeito ao processo de recuperação do dependente químico, objetivando ser efetivamente um núcleo protetor, e não causador dos conflitos enfrentados pelo sujeito. Mais que isso, ela precisa ter alguma esperança realista, não só fatalismo realista. Enfim, esses resultados apontam que os familiares de usuários de crack não possuem segurança na adesão destes ao tratamento, considerando o poder de dependência que esta droga possui. Através dessa discussão, verificou-se que a família de dependentes de crack necessita de acompanhamento profissional, a fim de saber lidar melhor com essa questão e colaborar, de forma efetiva, nas ações de cuidado direcionadas ao usuário de crack. 
Na representação dos profissionais entrevistados, foi encontrada apenas uma relação significativa entre duas evocações na análise de coocorrência: prisão e morte. Essa associação sugere que não existem boas perspectivas para o futuro de um usuário de crack. O questionamento sobre possíveis implicações dessas representações na atuação destes profissionais é retomado na discussão, uma vez que, quando não se acredita em determinado resultado, os meios para chegar até ele são prejudicados, senão, questionáveis.

Essas representações se assemelham às partilhadas entre os familiares de dependentes de crack, indicando que alguns trabalhadores não têm lidado com essa problemática com uma perspectiva de futuro positivo, remetendo a uma descrença relacionada à própria atuação, pois foi perceptível nesse estudo, a relação existente entre a expectativa de atuação e as suas crenças pessoais - representações apresentadas.

Nesta análise não foram encontrados sinais que fizessem referência à questão do tratamento da dependência dessa droga. Se mesmo os profissionais que atuam diretamente com esse público não veem alternativas para o futuro do usuário de crack, acredita-se que fica ainda mais difícil trabalhar pela sua aderência ao tratamento. Ao mesmo tempo é compreensível a desmotivação causada pela falta de resultados pelo trabalho prestado, porquanto essa ausência leva à descrença das estratégias e políticas atuais utilizadas no combate ao crack. Ballarin et al. (2011) aponta dificuldades dos profissionais em lidar com usuários de drogas, especialmente os de crack, muitas vezes entrando em conflito com os seus valores e crenças, interferindo diretamente na relação estabelecida com esses usuários. Assim, percebe-se a relevância em conhecer as representações compartilhadas por este grupo, com a finalidade de possibilitar uma reavaliação a respeito da sua prática profissional, levando em conta a necessidade da criação de ações e estratégias voltadas às especificidades do crack.

Enfim, analisando-se os discursos dos usuários, familiares e profissionais a partir das coocorrências e, sobretudo, partindo da hipótese de que, pode sim haver a recuperação (ou minimização de danos) da dependência do crack, os dados encontrados neste estudo apontam para uma possível ineficácia, pelo menos enquanto representação, de estratégias utilizadas no tratamento desses usuários. É visto, também, que a possibilidade de recuperação tem se mostrado muito complexa com as ferramentas disponíveis no sistema de saúde, o que remete a reflexões sobre os moldes de acompanhamento ofertados (Cruz, 2010). Portanto, questiona-se se a atual Política de Enfrentamento ao Crack tem conseguido alcançar aqueles resultados a que se propõem. Faz-se essa menção, em particular, considerando o número crescente de usuários e o alto índice de reincidência entre os usuários em tratamento, o que remete à ideia de que há necessidade da criação de novas ações voltadas para este público. Por outro lado, numa perspectiva mais preocupante, viu-se que os dados aqui relatados evidenciam uma desesperança transversalizada, alcançando usuários, familiares e até os próprios profissionais, ou seja, há de se rever práticas cotidianas, concepções e propostas de ação.

\section{Considerações finais}

Este estudo objetivou conhecer as representações sociais da expectativa de futuro do usuário de crack nas concepções de usuários de crack, familiares e profissionais de saúde inseridos nos CAPS. A partir dos resultados encontrados, constatou-se uma incerteza concernente às perspectivas de mudança entre os grupos analisados, no que se refere ao futuro do usuário de crack, sendo notória a descrença em relação a sua recuperação, principalmente para usuários e familiares. Essa ausência de perspectivas no futuro desse 
usuário é resultado do atual cenário presente em todo o mundo. Essa droga tem devastado famílias e destruído a vida de milhões de pessoas. Os resultados sugerem que esse indivíduo representa o insucesso na visão dos três grupos, como se o crack fosse um caminho sem volta, mas ainda assim é necessário buscar alternativas capazes de reduzir os prejuízos associados a esse consumo.

Consideram-se relevantes os dados apresentados, na medida em que contribuem para o conhecimento científico sobre esse fenômeno, embora se trate de opiniões e relato de pequenos grupos. A pesquisa apresentou limitações no tocante às poucas evocações encontradas entre os grupos na técnica destas, especialmente no grupo dos familiares, em que a dificuldade foi maior devido a relação deficitária existente entre os CAPS e as famílias dos dependentes químicos, segundo relato dos mesmos. Houve dificuldade, ainda, no acesso aos usuários de crack, considerando a baixa frequência desses indivíduos nos CAPS, além da dificuldade destes evocarem de forma significativa. No entanto, há possibilidade de que a pouca quantidade de evocações encontradas pode representar um consenso entre os entrevistados, denotando aspectos para além da técnica, ou seja, evoca-se pouco, também, quando o tema gera um impacto bastante comum entre os indivíduos. Deste modo, sugerese que novos estudos sejam realizados com uma amostra representativa dessa população, bem como torna-se interessante que se utilizem outras técnicas como instrumento de coleta de dados, a fim de que os seus resultados possam permitir uma discussão mais abrangente acerca do assunto.

Por fim, os resultados encontrados nesta pesquisa sinalizam preocupações importantes relacionadas a esse assunto, tais como os desafios enfrentados pelos profissionais de saúde, concernente a sua atuação frente à dependência química, notadamente do crack; as dificuldades de tratamento e medidas de prevenção; o aumento da criminalidade e comportamentos de risco; e o caráter fatalista que os três grupos apresentaram no que se refere à expectativa de futuro do usuário de crack. Ao apontar tais dificuldades, espera-se que esta discussão possibilite um contínuo debate sobre o tema entre a comunidade científica e governamental, intencionando possibilitar a criação de estratégias específicas e intervenções mais assertivas.

\section{Referências}

Abric, J. C. (2000). A abordagem estrutural das representações sociais. In A. S. P. Moreira \& D. C. Oliveira (Orgs.). Estudos interdisciplinares de representação social (pp. 27-38). Goiânia: AB.

Ballarin, M. L. G. S., Carvalho, F. B., Ferigato, S. H., \& Miranda, I. M. S. (2011). Percepção de profissionais de um CAPS sobre as práticas de acolhimento no serviço. O Mundo da Saúde, 35(2), 162-168.

Bastos, F. \& Bertoni, N. (2014). Pesquisa Nacional sobre o uso de crack: quem são os usuários de crack e/ou similares do Brasil? Quantos são nas capitais brasileiras? Rio de Janeiro: Editora ICICT/FIOCRUZ, Brasil.

Beck Júnior, A. (2010). Dependência do crack: Repercussões para o usuário e sua família. Monografia de Graduação, Curso de Enfermagem, Universidade Federal do Rio Grande do Sul, Porto Alegre, Brasil.

Cruz, M. S. (2010). O avanço do consumo como oportunidade para que a prática psiquiátrica entre ação. Debates, Psiquiatria Hoje, 2(3), 14-18.

Duailibi L. B., Ribeiro M., \& Laranjeira, R. (2008). Profile of cocaine and crack users in Brazil. Caderno Saúde Pública, 24(4), 545-557.

Haas, J., Angonese, A. S., \& Oliveira, L. A. (2011). A autoimagem de adolescentes do gênero masculino no tratamento da dependência química. Unoesc \& Ciência, 2(2), 110-118. 
Jodelet, D. (2001). Representações sociais: um domínio em expansão. In D. Jodelet (Org). As representações sociais (pp. 17-41). Rio de Janeiro: EDUERJ.

Kessler, F., \& Pechansky, F. (2008). Uma visão psiquiátrica sobre o fenômeno do crack na atualidade. Revista de Psiquiatria do Rio Grande do Sul, 30(2), 96-98.

Laranjeira, R., Madruga, C. S., Ribeiro, M., Pinsky, I., Caetano, R., \& Mitsuhiro, S. S. (2012). II Levantamento Nacional de Álcool e Drogas: O uso de cocaína e crack no Brasil. Universidade Federal de São Paulo, UNIFESP.

Martins, M. P. (2009). Perfil sócio-ocupacional do trabalhador de saúde mental do município de São Paulo. Saúde Coletiva, 7(6), 24-29.

Matos, M. T. S., Pinto, F. J. M., \& Jorge, M. S. B. (2008). Grupo de orientação familiar em dependência química: Uma avaliação sob a percepção dos familiares participantes. Revista Baiana de Saúde Pública, 32(1), 52 71.

Nappo, S. A., Galduróz, J. C., \& Noto, A. R. (1996). Crack use in São Paulo. Substance Use Misuse, 31(5), $565-$ 579.

Oliveira, D. C. (2013). Construção e transformação das representações sociais da AIDS e implicações para os cuidados em saúde. Revista Latino-Americana de Enfermagem, 21, 1-10.

Oliveira, L. G., \& Nappo, S. A. (2008). Caracterização da cultura de crack na cidade de São Paulo: padrão de uso controlado. Revista Saúde Pública, 42(4), 664-671.

Pratta, E. M. M., \& Santos, M. A. (2006). Levantamento dos motivos e dos responsáveis pelo primeiro contato de adolescentes do ensino médio com substâncias psicoativas. SMAD, Revista Eletrônica de Saúde Mental Álcool Drogas, 2(2), 1-17.

Rocha, C. (2010). Crack, a pedra da morte: Desafios da adiç̧ão e violência instantâneas. Biblioteca digital da Câmara dos Deputados. Brasília: Centro de Documentação e Informação.

Sá, C. P. (1996). Núcleo central das representações sociais. Petrópolis: Vozes.

Sanchez Z. M., \& Nappo, S. A. (2007). From the first drug to crack: The sequence of drugs taken in a group of users in the city of São Paulo. Substance Use Misuse, 42, 177-188.

Scheffer, M., Pasa, G. G., \& Almeida, R. M. M. (2010). Dependência de álcool, cocaína e crack e transtornos psiquiátricos. Psicologia: Teoria e Prática, 26(3), 533-541.

Secretaria Nacional de Políticas sobre Drogas. (2013). Estimativa do número de usuários de crack e/ou similares nas Capitais do País [online]. SENAD. Recuperado em 20 set., 2013, de http://portal.fiocruz.br.

United Nations Office on Drugs and Crime (UNODC) (2013). World Drug Report [online]. New York: UNODC. Recuperado em 19 jul., 2013, de www.unodc.org.

Vargens, R. W., Cruz, M. S., \& Santos, M. A. (2011). Comparação entre usuários de crack e de outras drogas em serviço ambulatorial especializado de hospital universitário. Revista Latino-Americana de Enfermagem, $19,804-812$.

Vergès, P. (2002). Conjunto de programas que permitem a análise de evocações: EVOC (Manual). Versão 5. Aix en Provence.

Wilbert, D. D. (2009). Representações sociais da infância e estilos de práticas educativas de mães professoras de crianças de 0 a 6 anos de idade. Tese de Doutorado, Programa de Pós-Graduação em Psicologia, Universidade Federal de Santa Catarina, Santa Catarina, Brasil. 